\title{
Theoretical Model to Analyze the Influence of Outsourcing on Industrial Business Value Creation
}

\author{
Pedro Costa Ramos \\ Department of Social and Organizational Sciences, High School of Management and Technology, \\ Polytechnic Institute of Santarém, Portugal
}

Received September 22, 2019; Revised November 22 , 2019; Accepted December 4, 2019

Copyright $\subseteq 2020$ by authors, all rights reserved. Authors agree that this article remains permanently open access under the terms of the Creative Commons Attribution License 4.0 International License

\begin{abstract}
This paper focuses on the discussion concerning the way how outsourcing decisions, regarding one or more of the companies' functions, can positively affect the internal value creation process and, thus, business performance, in both quantitative and qualitative terms. Based on the existing literature about Outsourcing a theoretical model was conceptualized to analyze and evaluate the influence of outsourcing on industrial and business value creation. The investigation process involved the collection of data through a questionnaire, applied to a representative set of SME's from the Portuguese economic fabric - resorting. The main conclusions to be taken from this research are: $(i)$ that outsourcing does present a verifiable set of statistically relevant direct and indirect effects upon the internal value creation process and, moreover, (ii) that outsourcing does generate a positive, and statistically relevant, indirect effect on business performance, through the internal value creation process.
\end{abstract}

Keywords Outsourcing, Strategy, Value Creation, Innovation, Performance

\section{Introduction}

Today, outsourcing is considered by a wide range of business-people, managers and academics as a management tool that can not only give flexibility to the firm and its cost structure but also as a way to access technology, competences and capital, among other benefits. Originally, the main aim of outsourcing was simply hiring a set of activities considered of low added value which contributed little or nothing to the firm's value chain, such as: payments, cleaning, security, sending mail [24,26,28,30].

Due to increased competitive intensity, firms are now obliged to concentrate their efforts and resources on what is indeed crucial to the business, opening up a range of opportunities to outsource processes, functions and activities which at first were not even considered for externalization and/or sub-contracting, among them financial functions, product innovation, information systems and fleets. Extending outsourcing to other firm dimensions has led to a qualitative change in the very concept, i.e., the fact of now including activities known as strategic for business, gives the concept another dimension and/or perspective: strategic outsourcing [6,27,32].

Choosing vertical disintegration, and therefore outsourcing, with a view to reinforcing or extending firms' central competences, should involve throughout the decision-making process all the firm's organs that may be involved and/or cooperate in defining the firm's global strategy $[2,11,21,31]$.

In the strategic analysis between handling internally and contracting outside, it is necessary to assess not only financial aspects but also the technological and commercial implications of each alternative in question, in order to facilitate the final decision. Strategic outsourcing aims to allow the firm to specialize in what is in fact crucial for its business, namely optimization of its core competences, perfecting its critical products and searching for opportunities, with the assurance that its partners and/or suppliers will develop the remaining competences and complementary products [2,30,31].

Only in this way is it possible to satisfy all critical factors for the firm's business success, without wasting resources, time and capital on redundant activities while also potentialising synergies of a strategic nature among cooperating firms $[10,31,32]$.

\section{Background of the Study+}

Companies must be prepared to adapt to new demands 
and global changes. The most integrated and flexible firms will certainly come out on top or at least survive in this new economy where diversity and complexity predominate allied to great transactional speed. That integration and flexibility does not only depend on their capacity to access financial, innovational and intellectual capital, but also on their own capacity to adapt to change imposed by new trends associated with the economic factor $[8,26,30]$.

The decision for vertical integration or disintegration of firms' services aims mainly to strengthen their nuclear competences and increase the medium and long-term competitiveness of their products. The decision-making process must consider not only the structures directly involved in the process, among them production, distribution and supply, but also the structures and organs that cooperate in defining the firm's organizational architecture and strategy $[14,17,29]$.

Strategic analysis of internal versus external production must consider, firstly, the financial aspects associated with the production process in analysis, and secondly, the technological and commercial impacts and implications inherent to each of the alternatives studied. Outsourcing of activities, or even the internalization of components, by firms is affected nowadays by various aspects, among them economic, financial, production and service, and no less importantly, in order to access new and better technology and competences. Intensified competition in industry in general has encouraged firms to promote Strategic Outsourcing networks and adopt joint actions to adjust to and/or align with the principal trends in the market and in competitors $[1,4,30]$.

Strategic Outsourcing aims to orient and lead the firm towards specialized, differentiated production, helping it to focus on what is in fact crucial and important for its continuity, its key competences, critical business processes and activities of value (acquiring in the market the competences to support internal processes).

Only in this way is it possible for firms choosing outsourcing to satisfy completely all the critical success factors necessary for correct implementation of this type of practice, without jeopardizing investments and above all taking advantage of possible synergies of a strategic and operational nature $[1,4,23,26]$.

Increasing business flexibility, or rather, the conception of global cooperation networks, was the aim of large multinational firms in industrialized countries. Rationalizing production and recourse to outsourcing was a sine qua non for the development of business networks, as conglomerates or inclusive support systems, a very similar situation to that currently operating in the financial sector. The development of the firm and its frontiers leads us to a new paradigm, the Network Firm. Internal frontiers, fed and strengthened by digital networks, and external frontiers resulting from alliances and partner relationships with clients and suppliers, give rise to an area where it is increasingly difficult to say where the firm begins and ends $[14,17,29]$.

In this organizational logic, outsourcing becomes increasingly a means of strategic action, namely in services related to production processes or sub-processes, logistics, information systems, research, training and skills development, among others. The aim is to ensure not only the sharing of assets and strategic competences, but also the sharing of operational and financial risk which are part of growing competitive intensity worldwide, and all the more so because small firms can function as suppliers or sub-contractors of a multi-business system $[4,14,24]$.

The network supposes the idea of sharing and trust. Indeed, for it to function, it will be necessary for the parties involved in the process, i.e., the parent company and subsidiary firms, to establish according to the ethical and deontological code followed, firstly, constructive and cooperative competition between them, and secondly, the formulation of common strategies and delimited interdependences. Much recent research on outsourcing has questioned the real reasons leading to its rapid spread, i.e., if its acceptance tends to be limited to only economic reasons or, on the other hand, if it is the result of following relentlessly with a minimum of calculation, preparation and suitability $[1,17,26]$.

Given this initial setting, showing some of the obstacles, potentials and situations inherent to outsourcing and despite a growing tendency to use it, globally, we are led to formulate the following central research question regarding management:

"...to what extent does outsourcing have a positive influence on the internal value creation process and how does this tend to be reflected in organizational performance?"

\section{Firm's Reasons for Outsourcing}

In a continually changing economic environment, success is achieved by those firms that, from the business perspective, tend to be more agile, flexible and dynamic in accompanying the evolution of the market and the competition. Today, the reasons for outsourcing are various and the decision not always made for the most obvious reasons, with it being up to each firm involved to decide on the true reasons leading them to choose this solution and/or management tool $[12,24,25,26]$.

The principal motivations leading firms to choose outsourcing belong to four main dimensions:

\section{- Financial Reasons}

Today, financial reasons still tend to be most frequently mentioned by firms, and consequently by their decision-making organs, as the most decisive and persuasive at the time of deciding. In practical terms, the 
financial benefits of outsourcing cover various aspects: cost reduction, cost control, access to capital, resource adjustment and taxation [7,19,22,30].

\section{- Business Reasons}

Reasons of a strategic nature including business ones are today among those with greatest weight in favor of outsourcing, due to the latter's ability to free up the firm and its human capital for central, essential questions of business development (core business). Firms that focus on what is essential and able to produce value can discover good opportunities in outsourcing, not only as a means to reduce costs but also as a means to improve service, the quality of processes and the business. So this category of reasons covers various aspects: concentrating on the activity, flexibility and risk-sharing, process improvement and organizational and functional change $[6,9,11,22]$.

\section{- Technical and Technological Reasons}

According to their nature and specialization, suppliers have technical proficiency and advanced technology which is usually beyond the capacity or interest of the client company. A firm with these capacities can provide their potential clients with access to the latest technology, improved platforms, techniques and/or new methods, generally speaking, access to a portfolio of new competitive advantages: the latest technology, information systems and human resources $[2,15,16,30]$.

\section{- $\quad$ Political Reasons}

Outsourcing provides a quick solution that can solve complex management problems where there are underlying internal conflicts and loss of control of processes (decisions of a behavioral, organizational and rational nature). Management organs are attracted by the idea that outsourcing will allow control of the costs of technology, information systems, human resources, infrastructure and others. So political reasons are induced by control of management and conflict-solving $[5,18,27,31]$.

\section{Theoretical Model and Investigation Hypotheses}

\subsection{Global Perspective of the Model}

The conceptual model presented aims to establish a number of positive interactions between outsourcing, the value creation process and organizational performance. The model analyzed is confirmed and results in a broad perspective of relationships between: (i) the different dimensions of outsourcing: Cost; Investment; Functional; Structural; Technological; Human Resources; Management Control and Conflict Management, the three dimensions of the internal value creation process: innovation, operations and customer service, as well as (ii) between these three dimensions, and finally, (iii) between them and organizational performance $[3,13,20]$.

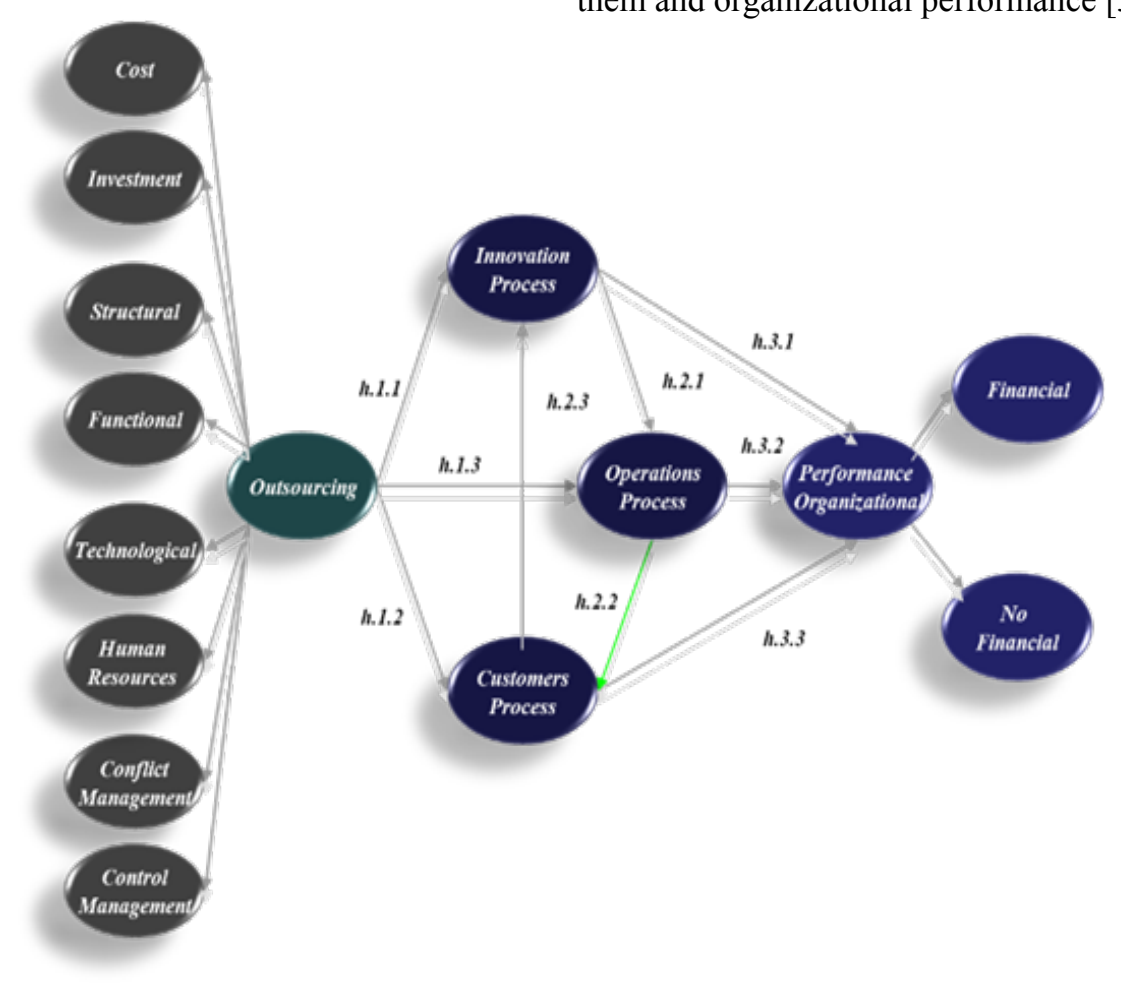

Figure 1. Conceptual model of the Influence of Outsourcing on Business Value Creation 
The model is made up of a total of 13 latent variables, where 12 of them are of an endogenous nature regarding the dimensions of outsourcing, internal value-creation process and business performance, and finally, one of an exogenous nature of a higher hierarchical order concerning the outsourcing instrument and/or tool itself.

\subsection{General Principles of the Conceptual Model and Investigation Hypotheses}

The traditional outsourcing system has evolved over the last decades to become much more strategic. Nowadays, potential activities for outsourcing have evolved from merely support activities such as accounting, cleaning, security and others, to strategic activities such as design and technology, product manufacture and sales. In order to support the conceptual model studied, the aim was to identify the relationships between outsourcing represented here by a system of motivations, the three dimensions of the internal value-creation process and organizational performance. From the above and considering the literature on the subject, the research hypotheses are formulated here, generically, in the form of the following propositions:

H.1. Outsourcing has a positive influence on the internal value-creation process through development of its dimensions of innovation, operations and customer service.

\section{Operational hypothesis:}

H.1.1. Outsourcing exerts a positive direct influence on the development of the innovation dimension.

H.1.2. Outsourcing exerts a positive direct influence on the development of the dimension of operations.

H.1.3. Outsourcing exerts a positive direct influence on the development of the customer service dimension.

H.2. The dimensions inherent to the internal value-creation process admit positive, mutual interactions, which contribute to the particular development of each dimension analyzed and of the very value-creation model in general.

\section{Operational hypothesis:}

H.2.1. The innovation dimension exerts a positive direct influence on the operations dimension.

H.2.2. The operations dimension exerts a positive direct influence on the customer service dimension.

H.2.3. The customer service dimension exerts a positive direct influence on the innovation dimension.

H.3. There is a positive, direct effect between the three dimensions analyzed - innovation process, operations process and customer-service process - and organizational performance.

\section{Operational hypothesis:}

H.3.1. The innovation dimension exerts a positive direct influence on performance.

H.3.2. The operations dimension exerts a positive direct influence on performance.

H.3.3. The customer service dimension exerts a positive direct influence on performance.

\section{Methodology}

\subsection{Research Strategy Adopted}

The strategy adopted in the research process requires the researcher to frame their methodological options in the different objectives to be achieved with each of them. This research is inserted in empirical-formal research methodologies (Ramos, 2012):

- the formulation of a set of hypotheses based on existing theory;

- the test of that same body of hypotheses, confronting it, where possible, with the information resulting from the observation of phenomena;

- critical reflection in order to subject the theory to the test of the facts observed, or not refute its veracity.

The methodological process aims to give form to the theory in testable statements, i.e., the hypotheses to be investigated through collection and subsequent treatment of empirical information, ending with a critical-conclusive analysis of the relationship between theory and practice. The quantitative aspect was worked on using structural equation modelling (SEM), a modelling technique used to test the validity of theoretical models that define causal and hypothetical relationships, between variables, operationalized in a set of linear equations, the relations between the latent and manifest variables forming the measurement model $[3,13,20]$.

\subsection{Target Population, Sample Selection and Data Collection Technique}

The universe considered in this study was for-profit firms with exporting capacity operating in Portugal. The research was extended to all sectors of economic activity, not only to extend it to the entire business world but also to obtain a valid number of respondents to allow achievement of the research process. The initial base included 3.230 companies, with the statistical methodology requiring a minimum number of 200 valid respondents, a situation which led to forming a sample of 1.330 companies. The investigation was carried out using a 7-point Likert scale questionnaire, sent by e-mail with a letter presenting the research project. 


\section{Exploratory Analysis of the Structural Elements of the Model}

This section aims to study the different structural elements that are part of the theoretical model. The first construct to be examined is what makes up the principals motivations to outsourcing: Financial; Business; Techniques; Policies. The second construct to be examine is the internal process of creating value, i.e., the different dimensions that make up it: innovation process; operations process; and customer service process. Finally, the third and last construct, the inherent of organizational business performance.

The process of examining the different elements of the conceptual model to outsourcing is essentially supported by multivariate statistical techniques and aims to support the estimation process of the conceptual model. The study led to the application of a process of analysis of main factors and components (PCAF), in a first phase over the dimensions that make up outsourcing: Financial; Business; Techniques; Policies, in order to evaluate the existence or not of correlations between the variables. The objective required to establish a solution that supported the number of factors imposed by the theoretical review - that would allow to illustrate the dimensions that make up the outsourcing variable but also of all other variables that constitute the model. The final solution of factor analysis for outsourcing after an optimization process tends to reflect the theoretical structural in line with the construction of the model:

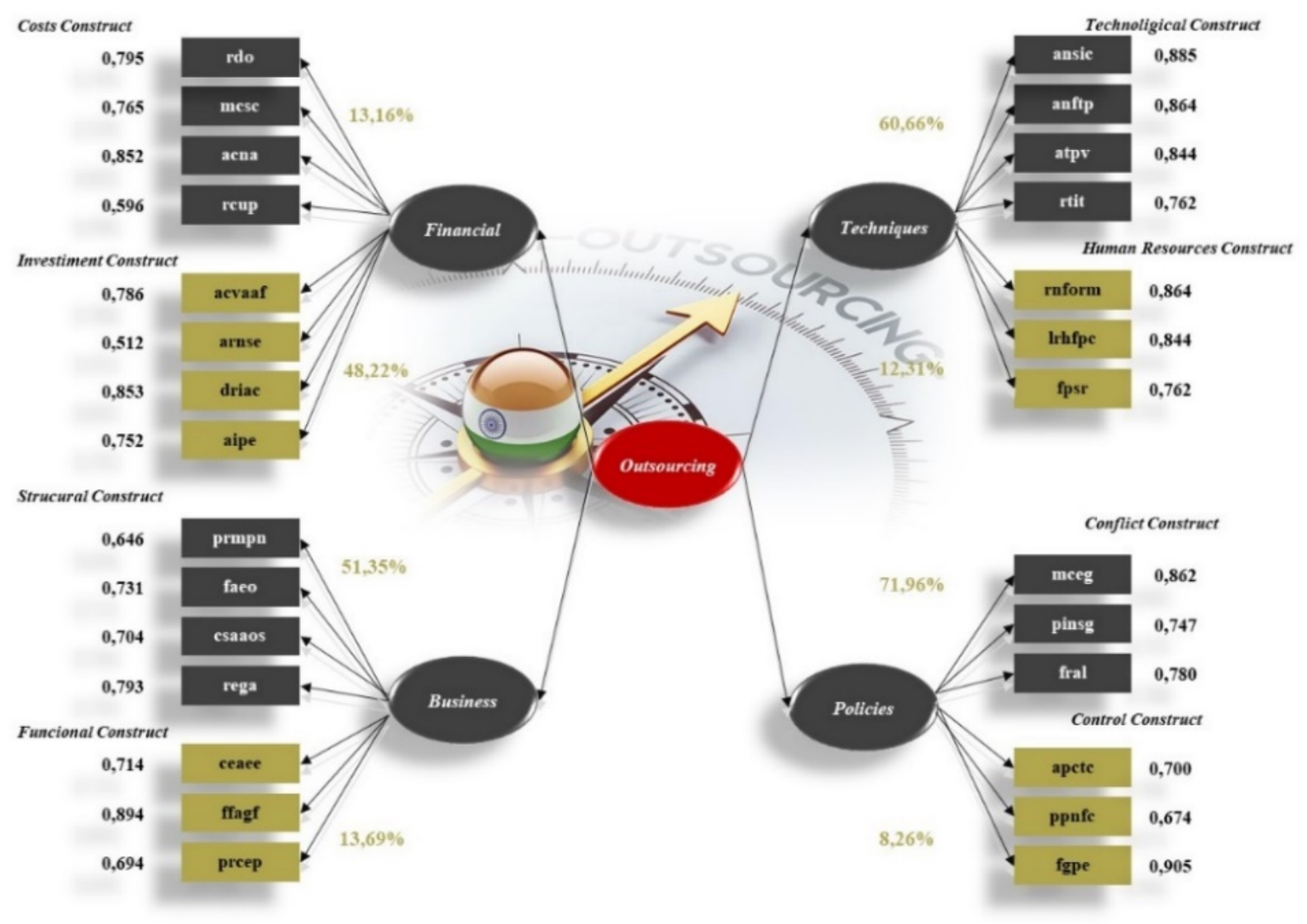

Figure 2. Factorial Structure Related to Outsourcing

Therefore, the final factorial solution reflects, for each of its outsourcing dimensions, the variance explained of the data per construct. In the dimension Financial, the Investment construct explains $48,22 \%$ of the variance data, in the Business dimension the Structural construct explains $51,35 \%$ of the variance; on the other and, in the Techniques dimension the Technological construct explains $60,66 \%$ of the variance, and finally, in the last dimension, Business dimension, the Conflict construct explains $70,96 \%$ of variance data, of course in each dimension. 


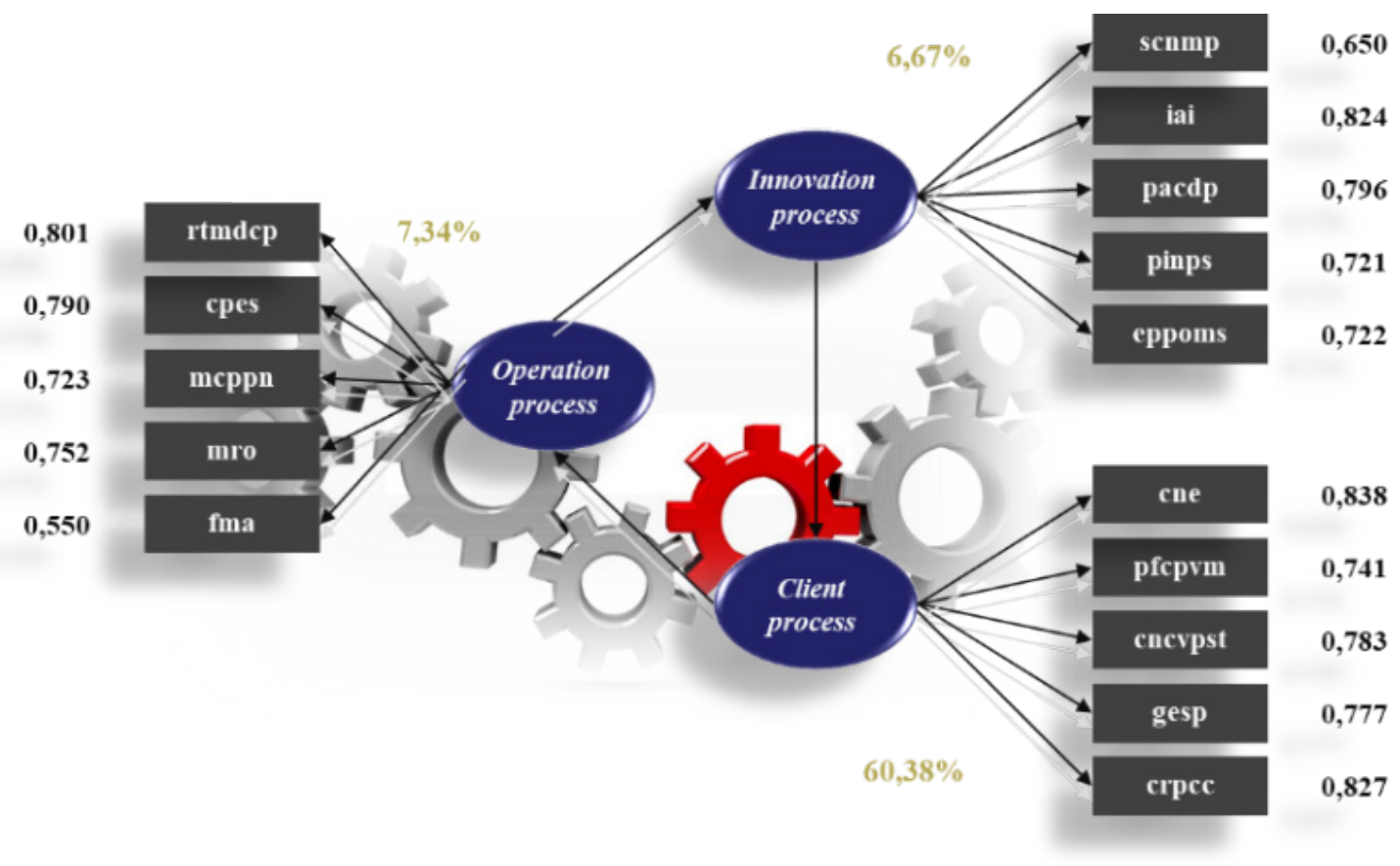

Figure 3. Factorial Structure Related to Value Creation Process

The factor analysis on the dimension "Value Creation Process" resulted in a tree factors solution in line with theory on the subject. The objective here was to align the factorial component with the theoretical aspect that allowed the design of the model, i.e., to group the items into three factors: operations process, innovation process and client process. The solution found explains $74,39 \%$ of the variance data. This analysis reveals that the "client process" factor, is the one that, most explains the variance dada $(60.3 \%)$ in side the dimension Value Creation Process.

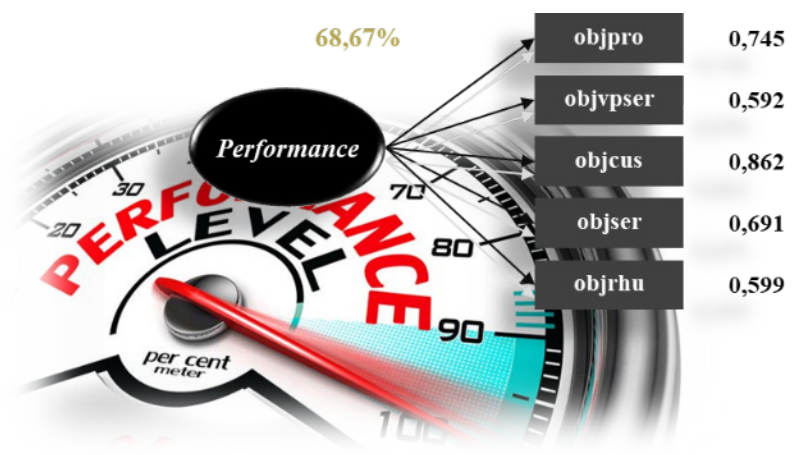

Figure 4. Factorial Structure Related to Performance

After an optimization process the final factorial structure to business performance preserves almost its integrity in line with the literature and explains $68,67 \%$ of the explained variance of the data. The initial structure had 7 items, but two of them, after the factor analysis, revealed values below the expectations, but not mortgage the final consistency of the drawn structure. A reliability analysis was performed for the group of manifest variables that make up all the constructs of the global model in order to determine the degree of consistency of all of them. The table below aims to present the different $\alpha$ values obtained for the items of the different constructs that make up the model to be estimated:

Table 1. $\alpha$ Cronbach by Construct

\begin{tabular}{|c|c|}
\hline Constructs & $\alpha$ Cronbach \\
\hline Costs & 0,811 \\
\hline Investment & 0,809 \\
\hline Structural & 0,845 \\
\hline Functional & 0,741 \\
\hline Technological & 0,918 \\
\hline Human Resources & 0,811 \\
\hline Conflicts Management & 0,936 \\
\hline Control Management & 0,884 \\
\hline Innovation process & 0,925 \\
\hline Operations process & 0,912 \\
\hline Client process & 0,940 \\
\hline Performance & 0,895 \\
\hline
\end{tabular}

The final $\alpha$ values presented here largely transpose the reference value, i.e., $\alpha \mathrm{Ch} \geq 0,7$ acceptable to complete the good internal consistency of the data. 


\section{Estimation and Confirmatory Analysis of the Conceptual Model}

The model presented here already reflects the final version resulting from application of a process of model optimization and adjustment. The paths of Outsourcing $\rightarrow$ Client $\left(\theta_{O t \rightarrow C l}=0,186 ; \mathrm{SE}=0,057 ; \beta_{o t \rightarrow C l}=0,13 ; \mathrm{p}=0,090\right)$, Client $\rightarrow$ Performance $\left(\theta_{C l \rightarrow D p}=0,083 ; \mathrm{SE}=0,061 ; \beta_{C l \rightarrow D p}=0,15 ; \mathrm{p}=0,170\right)$ and Operations $\rightarrow$ Performance $\left(\theta_{O p \rightarrow D p}=0,136 ; \mathrm{SE}=0,072 ; \beta_{O p \rightarrow D p}=0,22 ; \mathrm{p}=0,059\right)$ were eliminated as they had no statistical significance, without losing the quality of adjustment

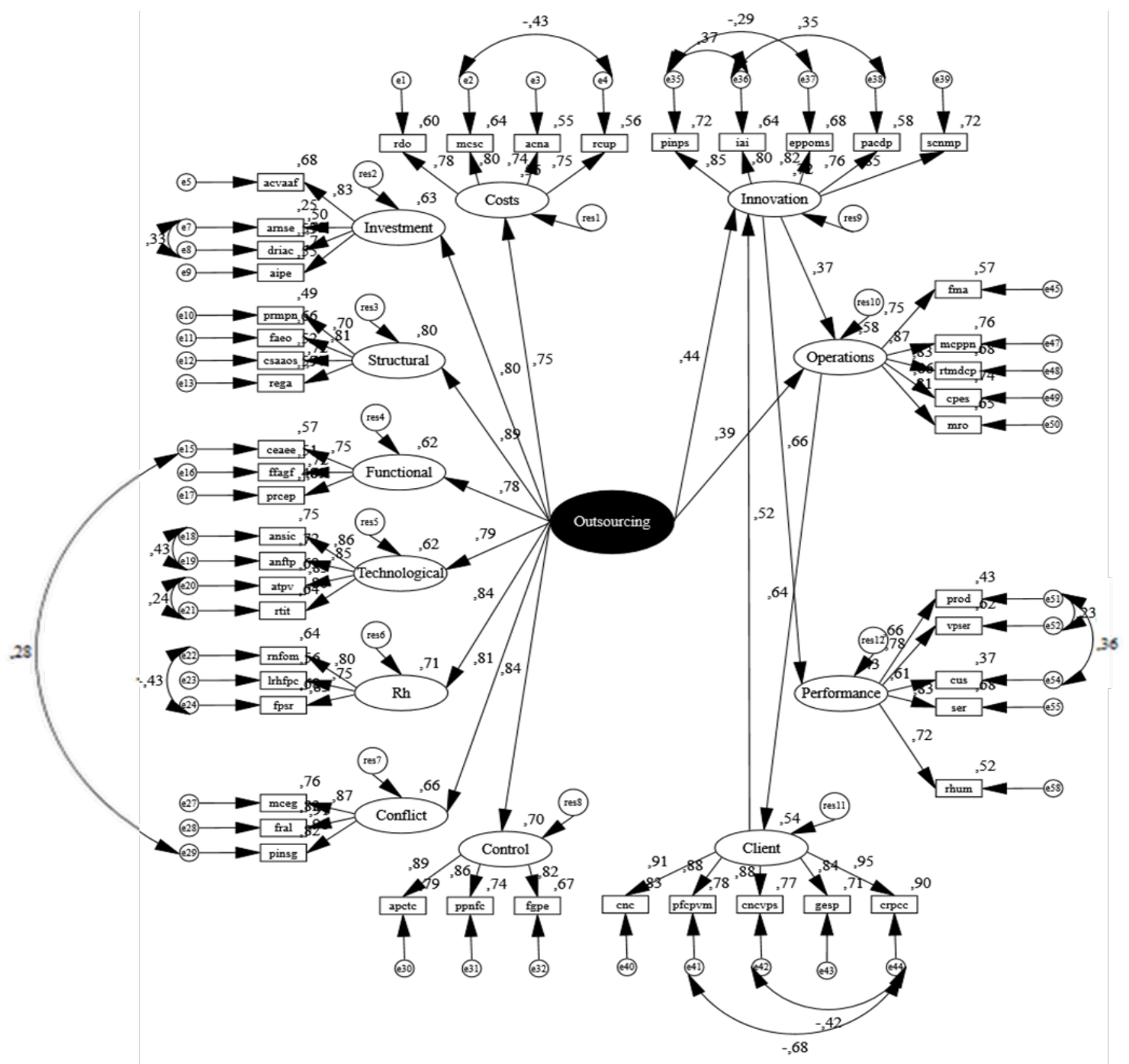

Figure 5. Causal Model for Global Outsourcing

Standardized results: $X^{2} / d f=1,714$; $\mathrm{CFI}=0,901 ; \mathrm{GFI}=0,732 ; \mathrm{PCFI}=0,841 ; \mathrm{PGFI}=0,655$ and RMSEA $=0,060$.

The remaining paths of the model were found to be statistically significant, contributing to the final validation of the model: Outsourcing $\rightarrow$ Innovation $\left(\theta_{O t \rightarrow I n}=0,553 ; \mathrm{SE}=0,072 ; \beta_{o t \rightarrow C l}=0,44 ; \mathrm{p}=0,001\right)$; Outsourcing $\rightarrow$ Operations $\left(\theta_{O t \rightarrow o p}=0,441 ; \mathrm{SE}=0,095 ; \beta_{o t \rightarrow C l}=0,39 ; \mathrm{p}=0,001\right) ;$ Innovation $\rightarrow$ Operations $\left(\theta_{I n \rightarrow o p}=0,314 ; \mathrm{SE}=0,088 ; \beta_{o t \rightarrow C l}=0,37\right.$; $\mathrm{p}=0,001)$; Client $\rightarrow$ Innovation $\left(\theta_{C l \rightarrow I n}=0,841 ; \mathrm{SE}=0,090 ; \beta_{o t \rightarrow C l}=0,64 ; \mathrm{p}=0,001\right) ;$ Operations $\rightarrow$ Client $\left(\theta_{O p \rightarrow C l}=0,477\right.$; $\left.\mathrm{SE}=0,060 ; \beta_{o t \rightarrow C l}=0,52 ; \mathrm{p}=0,001\right)$. Finally, the last path of the model, Innovation $\rightarrow$ Performance $\left(\theta_{I n \rightarrow D p}=0,386 ;\right.$ $\left.\mathrm{SE}=0,048 ; \beta_{O p \rightarrow D p}=0,66 ; \mathrm{p}=0,001\right)$.

The final $M_{G}$ model presents for the indicators of absolute adjustment quality $X^{2} / d f$, Rmr, Gfi, values of 1,716 , 0,141 and 0,732 , respectively. The $X^{2} / d f$ figure indicates good adjustment, while the Rmr and Gfi indicators are slightly below the acceptable references, very close to the limits considered adequate. The indicators of relative and/or incremental adjustment quality for the indices of Nfi and Rfi are a little below the recommended references, outside the adequate limits. The indicators of Nfi and Rfi are inappropriate for small samples and so some prudence is necessary when interpreting and assessing the results, as this can lead to biased analyses (they are greater the bigger the sample). 
The other indicators of incremental adjustment, Cfi, Ifi and Tli, present values within recommended and acceptable intervals, with the first two values indicating good adjustment of 0,901 and 0,902 , respectively. The indices of parsimonious adjustment, Pgfi, Pnfi and Pcfi, present final values of 0,655, 0,740 and 0,842, respectively. The Pgfi and Pnfi indices indicate good adjustment, within the recommended parameters, while the Pcfi index is considered as a very good adjustment. The Rmsea index of ovulational discrepancy assesses the model's level of adjustment through the number of g.l. added, i.e., it penalizes as a way of compensating for the model's adjustment (tending to favour more complex models), and so has an important role in assessing the final adjustment.

The final value calculated for the Rmsea index was 0,060 , considered as a good adjustment. The Rmsea index was tested for an I.C. of $90 \%$ with the result revealing good adjustment, the values found meaning that with $90 \%$ probability, the Rmsea in the population is between 0,055 and 0,064. Consequently, with all the indicators assessed, the final $M_{G}$ model reflects a very reasonable level of final adjustment quality.

\section{Analysis of Direct and Indirect Effects on the Global Model}

The effect of the motivation structure for outsourcing on each of the pillars of the value creation process is projected beyond that which is given directly by the causal relationship, significant or not, between both. In addition to the direct effect, there is also a set of indirect effects, resulting from the circular structure "originating" from the value creation process, when combined with the first effects, reflect the total effect produced.

Table 2. Outsourcing Effects Matrix on the Value Creation Process

\begin{tabular}{|c|c|c|c|}
\hline \multicolumn{4}{|c|}{ Effects of Outsourcing Motivations System } \\
\hline on: & Indirect efect & Direct efect & Total efect \\
\hline Innovation process & 0,437 & 0,208 & 0,645 \\
\hline Operations process & 0,386 & 0,237 & 0,623 \\
\hline Human Resources & $(*)$ & 0,397 & 0,397 \\
\hline
\end{tabular}

(*) A non-significant relationship from a statistical point of view.

(**) Standardized values.

Considering valid the circular assumption suggested by the theoretical literature to the "Value Creation Process", i.e., the output generated by one of the dimensions serves as input to the next dimension of the chain and so on. Therefore, the circular structure also reflects a set of indirect effects, resulting from the underlying relationships, which are presented below:

Table 3. Value Creation Process Effects

\begin{tabular}{|c|c|c|c|c|c|c|}
\hline Effects of: & \multicolumn{2}{|c|}{ Innovation process } & \multicolumn{2}{c|}{ Operations process } & \multicolumn{2}{c|}{ Client process } \\
\hline On: & Indirect efect & Direct efect & Indirect efect & Direct efect & Indirect efect & Direct efect \\
\hline Innovation process & -- & 0,140 & $\left(^{*}\right)$ & 0,380 & 0,523 & 0,073 \\
\hline Operations process & 0,368 & 0,051 & -- & 0,140 & $\left(^{*}\right)$ & 0,219 \\
\hline Human Resources & $\left(^{*}\right)$ & 0,267 & 0,826 & 0.089 & -- & 0,140 \\
\hline
\end{tabular}

(*)Relationship not considered in model.

(**) Standardized values.

The table below reflects the flow of direct and indirect effects exercised by the "Value Creation Process" on business performance, but also the positive indirect effect created by the motivations system for outsourcing on performance through the value creation process.

Table 4. Business Performance Effects

\begin{tabular}{|c|c|c|c|c|c|}
\hline On: & Effects of: & Outsourcing & Innovation & Operations & Client \\
\hline \multirow{3}{*}{ Performance } & Direct efect & $\left(^{*}\right)$ & 0,657 & $\left(^{* *}\right)$ & $\left(^{* *}\right)$ \\
\cline { 2 - 6 } & Indirect efect & 0,423 & 0.092 & 0,249 & 0,391 \\
\cline { 2 - 6 } & Total efects & 0,423 & 0,748 & 0.249 & 0,391 \\
\hline
\end{tabular}

(*)Relationship not considered in model.

(**)A non-significant relationship from a statistical point of view.

$(* * *)$ Standardized values. 
The results calculated for the total effects of the innovation process on organizational performance are more than evident. The indirect effect caused by the system of motivations for outsourcing on business performance through the creating value process is significant which reveals its importance for the management of companies. The indirect effects generated by the operations and client processes on business performance, through the circular structure for value creation, are positive, i.e., in a moderate perspective, especially the operations, but important for model validation.

\section{Conclusions}

Considering the results obtained in the confirmatory analysis, we can infer that today outsourcing is a widely accepted management instrument and/or tool and already implemented to some degree by a significant number of companies operating in the Portuguese market (based on the final sample). It was also clear that the purpose of outsourcing goes beyond the simplified view centered on reducing costs. Today, when firms choose outsourcing of a business activity and/or process, they aim to obtain and/or access a series of benefits, among them: competences; technology; investment; control; organizational flexibility.

The sectors of activity resorting most to outsourcing to support their principal activity are mainly Manufacturing Industry and Wholesale and Retail, with approximately $27,9 \%$ and $17,8 \%$ of the sample, respectively. Some other sectors of economic activity, namely Construction and Financial and Insurance Activities, present figures which are less expressive but still relevant, i.e., with $12,0 \%$ and $8,7 \%$ of the sample, respectively. Currently, the functions or activities most outsourced in Portugal are those involving the aspects of Organization, Information Systems and Financial Systems, with the first two presenting a figure of $17,8 \%$ and the third a figure of $16,3 \%$.

The effect of the motivation structure for outsourcing on each of the pillars of the value-creation process is projected beyond what is produced directly by the causal, significant or non-significant relationship between each. Besides the direct effect there is also a set of indirect effects resulting from the circular structure originating from the value-creation process, which, when combined with the first, reflects the total effect produced on performance. The following table summarizes the cause-effect relationships initially proposed - research hypotheses - and the respective decisions made arising from the model estimation process:

Table 5. Hypotheses and decisions

\begin{tabular}{|c|c|c|}
\hline Relations & Hypotheses & Decision \\
\hline Outsourcing System $\rightarrow$ Innovation process & h.1.1 & Not Rejected \\
\hline Outsourcing System $\rightarrow$ Operations process & h.1.2 & Not Rejected \\
\hline Outsourcing System $\rightarrow$ Client process & h.1.3 & Rejected \\
\hline Innovation process $\rightarrow$ Operations process & h.2.1 & Not Rejected \\
\hline Operations process $\rightarrow$ Client process & h.2.2 & Not Rejected \\
\hline Client process $\rightarrow$ Innovation process & h.2.3 & Not Rejected \\
\hline Innovation process $\rightarrow$ Performance & h.3.1 & Not Rejected \\
\hline Innovation operations $\rightarrow$ Performance & h.3.3 & Rejected \\
\hline Client process $\rightarrow$ Performance & h.3.3 & Rejected \\
\hline
\end{tabular}

Overall, the results obtained in estimating the model confirm the existence of direct, statistically significant relationships between outsourcing and innovation and operations processes. Furthermore, due to the circular structure, i.e., relations between the value-creation processes, all of them positive and significant, the effect of outsourcing on the value-creation structure is ultimately reflected in customer service through the indirect effects - a positive effect on the whole.

Although not all the relationships established had statistically significant results, leading to rejection of three relationships - research hypotheses - the final results are globally relevant and do not detract from the validity of the research model proposed. Consequently, outsourcing today is taken to be a strategic management instrument available to companies not only for the purpose of reducing and controlling fixed costs but also in order to access more and better up-to-date technology, human resources, organizational flexibility and others.

That is, a situation leading us to the concept of a motivation system that is no more than the sum of all these components (although the weights may differ) and as seen, when well and/or strategically used produces a positive effect on the value-creation process. Applying structural equation models to this research - to validate the theoretical conceptual model - was seen to be appropriate, considering the multiple relationships of dependence and interdependence implied by the phenomenon itself and represented by the model. 


\section{Theoretical and Managerial Implications}

The contributions of this paper research can be noted in two different perspectives: contribution to science in management and contribution to the management of organizations. The contribution to management science stems from the originality of the proposed causal model that, supported on the structural equations system, is a new perspective of addressing the concept of outsourcing. The approach is, in itself, innovative in establishing a set of cause-effect relationships between outsourcing itself, the internal process of value creation and organizational performance. The model leaves open its possible application to other areas of science in management, including: strategic marketing, management accounting, decision theory, human resources, finance, organization and other projects whose value is significant for the Science. On the other hand, the model also leaves open the hypothesis of a new confirmatory analysis, using another database, possibly with international companies, in order to try to confirm the assumptions and results obtained, as well as to give new clues to development of new theoretical models.

The contribution to the management of organizations, regardless of its industrial sector, reverts to the results obtained from the estimation of the model, because they confirm the positive effect that outsourcing produces on the internal process of value creation and which, after being internalized, contributes to an improvement financial and operational performance of companies in general. The results obtained thus remove the simplistic and preconceived idea that the use of outsourcing by companies is only intended to reduce fixed costs with human resources and transactions and/ or operations. Outsourcing is an instrument that supports its essential in a motivation system that, when used in a strategic way and integrated by management bodies, contributes to the development of the company. The study also refutes the idea that an outsourcing process on one activity, or even more activities of the company, can therefore be thought by the different companies administrations, but without first carrying out the field work necessary to identify which activities, benefits, and objectives to achieve with the process in order to identify the pros and cons to facilitate decision-making.

In summary, the research work developed here, ensured the academic issues, assumes itself, as a reflection instrument on the real objectives to be achieved with outsourcing, but also to assist managers, administrations and entrepreneurs on the decision-making processes.

\section{Future Research Opportunities}

The research opportunities this work raises for the future is not only stemmed from a further application of the study now wider and also in order to confirm unconfirmed relationships. Another perspective for research would be the attempt to apply the model to a broader economic dimension, i.e., consider the effect of offshoring outsourcing - motivations - on the process of creating a country's value and whether this effect resonates positively sustained growth in gross domestic product. The model to be estimated would require changes in the basic structure of the model to give it a more macroeconomic perspective, i.e., supported in others "concepts" such as: captive offshore and offshore outsourcing, today already considered valid for business growth on outsourcing in the coming years, namely in emerging economies.

Thus, we are highlighting some of the researchers who have devoted much of their time to the study of the phenomenon of offshore outsourcing and who with their research have contributed to the dynamism of knowledge by different communities, between them: Richard Vietor (2007) and Michael Corbett (2004). These are some of the open clues, for future investigation in this area of outsourcing, ready to be explored and waiting for interested investigators.

\section{REFERENCES}

[1] Allweyer, T. (2016), BPMN 2.0: Introduction to Standard for Business Process Modeling, 2 Ed., Herstellung und Verlag, Bod Books on Demand, Norderstedt. W. Zabierowski, A. Napieralski. Chords classification in tonal music, Journal of Environment Studies, Vol.10, No.5, $50-53$.

[2] Benaroch, M., Lichtenstein, Y. \& Fink, L. (2016), Contract Design Choices and the Balance of Ex-Ante and Ex-Post Transaction Costs in Software Development Outsourcing, MIS Quarterly, SSRN, Vol. 40. No 1.

[3] Byrne, B. (2009), Structural Equations Modelling with Amos: Basic Concepts, Applications, and Programing, $2^{\circ}$ Ed., New York: Taylor \& Francis Group.

[4] Burke, W. (2018). Organization change: Theory and Practice, 5 Ed., Sage Publications, California.

[5] Carl, P. Maertz, Jr., Jack, W, Cynthia, L \& Michael C. (2010), Downsizing Effects on Survivors: Layoffs, Offshoring, and Outsourcing, Industrial Relations: Journal of Economy and Society, Vol. 49, pp. 275-285.

[6] Choi, J., Ju, M., Kotabe, M., Trigeorgis, L. \& Zhang, X. (2017). Flexibility as firm value driver: Evidence from offshore outsourcing, Global Strategy Journal, SMS, Vol. 8, Issue 2, pp.351-376.

[7] Cohen, L. \& Young, A. (2006), Multisourcing: Moving Beyond Outsourcing to Achieve Growth and Agility, Harvard Business Scholl Press, Boston, Massachusetts.

[8] Cognini, R., Corradini, F., Gnesi, S., \& Polini, A. (2016). Business process flexibility - a systematic literature review 
with a software systems perspective, Springer Science, Business Media, Vol. 20, Issue 2., pp. 343-371.

[9] Farok, J., Vikas, K., Sumit, K. \& Torben, P. (2010), Reconceptualizing the Firm in a World of Outsourcing and Offshoring: The Organizational and Geographical Relocation of High-Value Company Functions, Journal of Management Studies, Vol. 47, pp. 1417-1433.

[10] Feng, T., Ren, Z. \& Zhang, F. (2019), Service Outsourcing: Capacity, Quality and Correlated Costs, Production and Operations Management, Vol. 28, issue 3, 2019.

[11] Grinpe, C. \& Kaiser, U. (2010), Balancing Internal and External Knowledge Acquisition: The Gains and Pains from R\&D Outsourcing, Journal of Management Studies, $V^{\circ} 47$, pp. 1483-1509.

[12] Guo, P., Song, J., \& Wang, Y. (2010), Outsourcing Structures and Information Flow in a three-tier Supply Chain, International Journal of Production Economics, Vol. 128, pp 175-187.

[13] Hair, J., Anderson, R., Tatham, R., Black, W. \& Barry, J. (2009). Análise Multivariada de Dados. 6th Ed., Porto Alegre, Bookman

[14] Harmon, P. (2019). Business Process Change, 4 Ed., Morgan Kaufmann Publishers, Elsevier.

[15] Jakob, R. (2010), Whose Job Goes Abroad? International Outsourcing and Individual Job Separations, The Scandinavian Journal of Economics, Vol. 112, pp 339-360.

[16] Jenster, P., Pedersen, H., Plackett \& Hussey, D. (2005), Ousourcing-Insourcing, John Wiley\& Sons, ltd., The Atrium, England.

[17] Kumar, A. (2018). Business Process Management, 1 St, Edition, Routledge, New York.

[18] Linder, J. (2004), Outsourcing for Radical Change: A Bold Approach to Enterprise Transformation, Amacon, America Management Association, Accenture LLP, Broadway, New York.

[19] Mani, D. \& Barua, A. (2010), An Empirical Analysis of the Impact of Information Capabilities Design on Business Process Outsourcing Performance, MIS Quarterly Vol. 34, $\mathrm{N}^{\mathrm{o}} 1$, pp. 39-62.

[20] Maroco, J. (2010), Analysis of Structural Equations: theoretical fundamentals, Software and applications, Report Number Lda., Lisboa.

[21] Mark, P., Desouza, K. e Bonifazi. C. (2007), The Outsourcing HandBook: How to Implement a Successful
Outsourcing Process, British Library Cataloguing-in-Publication Data, London.

[22] Munch, J. e Skaksen, J. (2009), Specialization, Outsourcing and Wages, Review of World Economics, Vol. 145, N. ${ }^{\circ} 1$, pp. $57-73$

[23] Nandakumar, M. (2010), Outsourcing Design, Process and Performance, John Wiley \& Sons Ltd., Cambridge University Press, pp. 218-230.

[24] Oshri, I., Kotlarsky, J. \& Willcoks, L. (2015), The Handbook of Global Outsourcing and Offshoring, Palgrave Macmillan, Offshoring: The Definitive Guide to Strategy and Operations, 3 Ed., Palgrave Macmilan, USA.

[25] Power, M., Desousa, K. \& Bonifazi, C. (2006), The Outsourcing Handbook: How to Implement a Successful Outsourcing Process, Kogan Page Limited, Philadelphia, United States.

[26] Ramos, P. (2012). Strategic Outsourcing in Business Activity: Main Trends and Impacts in the Productive Process, in the Value Chain and in the Organizational and Functional Model of the Companies. $\mathrm{PhD}$ Thesis, University of Évora.

[27] Spithoven, A. \& Teirlinck, P. (2016), Internal capabilities, network resources and appropriation mechanisms as determinants of R\&D Outsourcing, Research Policy, Vol. 44, Issue 3, pp. 711-725.

[28] Sue, N., Levina, N. \& Ross J. (2016), The Long-Tail Strategy for IT Outsourcing, MITSloan Management Review, Vol. 52. No2.

[29] Tarhan A., Turetken, O. \& Reijers, H, (2016). Business process maturity models: A systematic literature review, Information and Software Technology, Vol. 75, pp. 122-134.

[30] Tsay, A., Gray, J., Noh, I. \& Mahoney, T. (2018). A Review of Production and Operations Management Research on Outsourcing in Supply Chains: Implications for the Theory of the Firm, Production and Operations Management, Vol. 27, Issue 7, pp. 1177-1220.

[31] Zhu, W., Stephen, C., Wanga, Z. \& Zhao, X. (2017), The role of outsourcing management process in improving the effectiveness of logistics outsourcing, International Journal of Production Economics, Vol. 188, pp. 20-40.

[32] Zou, Z, Wang, J., Deng, G. \& Chen, H. (2016), Third-party remanufacturing mode selection: Outsourcing or authorization? Transportation Research Part E: Logistics and Transportation Review, Vol. 87, pp 1-19. 